\title{
Texture Analysis in Ultrafine Grained Coppers Processed by Equal Channel Angular Pressing
}

\author{
Oscar Fabián Higuera ${ }^{\mathrm{a}, \mathrm{b} *}$, J. M. Cabrera ${ }^{\mathrm{a}, \mathrm{c}}$ \\ a Departamento de Ciencia de los Materiales e Ingeniería Metalúrgica, \\ Universidad Politécnica de Cataluña. Barcelona, España \\ ${ }^{\mathrm{b}}$ Facultad de Ingeniería Mecánica, Universidad Tecnológica de Pereira, \\ Vereda La Julita, Pereira, Colombia \\ ${ }^{\mathrm{c}}$ Fundació CTM Centre Tecnológic, Manresa
}

Received: November 3, 2012; Revised: December 19, 2012

\begin{abstract}
Electrolytic tough pitch (ETP) and fire refined high conductivity (FRHC) copper samples were severely deformed at room temperature by equal channel angular pressing (ECAP) up to 16 passes ( $\varepsilon \sim 1$ per pass), following route $\mathrm{Bc}$. The effect of the initial texture on the evolution of texture after the ECAP process for both materials was analyzed. The annealed materials present a marked anisotropy, with a texture controlled by the $<110>$ fiber. According to the orientation distribution function (ODF), this initial behavior allows the presence of a strong $C(\{001\}<110>)$ component after the first two ECAP passes in both coppers. However in the second pass the $\mathrm{C}$ component significantly increases in the FRHC copper, whereas the ETP copper presents a much more balanced behavior of the $\mathrm{A}_{1}^{*}$ (111) [ $\overline{1} \overline{1} 2]$ and $\mathrm{A}_{2} *(111)[11 \overline{2}]$ components. The textures obtained for both coppers after each ECAP pass exhibit predominant orientations with continuous distributions along the orientation fiber with simple shear texture.
\end{abstract}

Keywords: Equal channel angular pressing (ECAP), EBSD, copper, texture

\section{Introduction}

Materials with ultrafine or nanometric grain size have attracted considerable interest because of their unique properties compared with conventional materials ${ }^{1}$. The equal-channel angular pressing (ECAP) method, in which severe plastic-deformation is imposed through simple shear, is capable of refining the grain size up to $100-200 \mathrm{~nm}$ in many metallic alloys and composites in the form of relatively large bulk billets ${ }^{2}$. As the material deforms, it develops texture due to crystal reorientation, according to the slip systems given by its crystallographic structure. However, additional texture components may be present depending on the processing conditions, and can be related to in situ recrystallization processes for instance. The evolution of the deformation texture with strain has been analyzed by many researchers $^{3-6}$. In this work the effect of the initial texture and the appearance of in-situ annealing during ECAP on texture for two commercial purity coppers was analyzed. The texture was represented by the orientation distribution function (ODF), because it presents the small changes that may appear in the location of texture components.

\section{Experimental Procedure}

In this study, cylindrical samples with $10 \mathrm{~mm}$ in diameter and $60 \mathrm{~mm}$ in length of electrolytic tough pitch

*e-mail: osfahico@gmail.com
(ETP) copper with $99.96 \%$ purity and fire refined high conductivity (FRHC) copper with $99.91 \%$ purity were subjected to annealing at $600{ }^{\circ} \mathrm{C}$ under inert atmosphere (Argon) for 30 minutes. Subsequently, the materials were subjected to severe plastic deformation by ECAP technique at room temperature until a maximum deformation equivalent to 16 , following route $\mathrm{Bc}$ (sample rotation of $90^{\circ}$ along its longitudinal axis in the same direction after each pass). The form of the insert, made out of two symmetrical parts, causes the appearance of a slight longitudinal line scratched on the sample after each pass. This line helps to guide the rotation of the sample between passes. The configuration of the die and the reference system used in this study are represented in Figure 1. The equivalent deformation per pass is approximately $1^{7}$. The extrusion rate was $0.02 \mathrm{~m} / \mathrm{s}$ and molybdenum disulphide was used as lubricant. EBSD samples were cut from the center of the ECAP billets and mechanically polished until $0.02 \mu \mathrm{m}$ colloidal silica solution. EBSD measurements were performed on the transversal plane (XY plane) using a scanning electron microscope (SEM) with field emission gun JEOL JSM-7001F (at a $20 \mathrm{kV}$ voltage) using HKL Channel 5 Oxford Instruments software. The measurement areas for the EBSD analysis were $360 \times 300 \mu \mathrm{m}^{2}$ for the annealed materials, $150 \times 120 \mu^{2}$ after 1 pass through ECAP, $75 \times 60 \mu \mathrm{m}^{2}$ after 4 passes and $25 \times 20 \mu \mathrm{m}^{2}$ after 8 and 16 passes by ECAP, for both coppers. 


\section{Results and Discussion}

Annealed material. The recrystallization process of a deformed metal involves the nucleation and growth of new undeformed grains in the deformed matrix, which are characterized by the formation and movement of high angle grain boundaries. This leads to crystallographic texture changes in a material because of the changes in the distribution of crystallographic orientations during the recrystallization process. The most significant orientations positions of the recrystallization texture for a FCC material

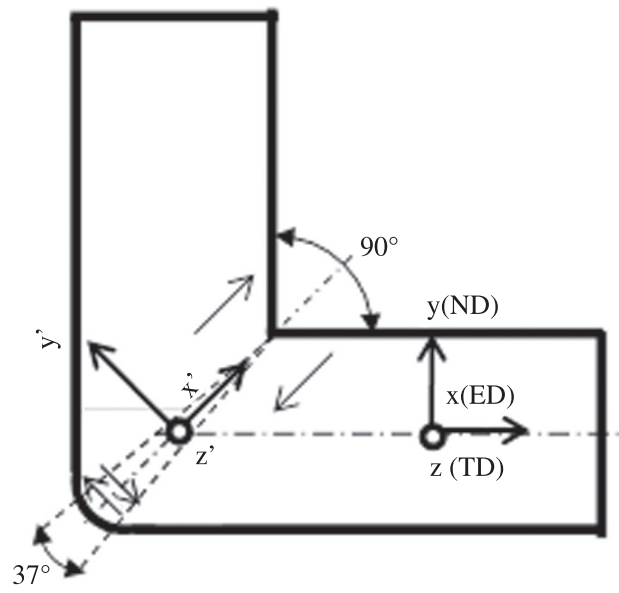

Figure 1. Die configuration and the reference system used in this study. have been identified by Humphreys ${ }^{8}$ and $\mathrm{Segal}^{9}$. Figure 2 shows the ODFs for the annealed ETP and FRHC copper samples prior to the ECAP process. The annealed materials were analyzed in triclinic symmetry in order to identify the initial symmetry. It can be noticed that both coppers present an orthorhombic symmetry with a weak deformation texture, which could be an indication of an incomplete annealing process. Materials with a medium stacking fault energy (SFE), such as copper, typically present cube recrystallization texture $\{001\}<100>$ with their respective first generation twins $\{122\}<212>^{10}$. It is considered that this kind of textures comes from nuclei which emerge from structures in the form of bands, called cube bands, which are part of a deformed microstructure. These cube bands can be considered as transition bands or deformed grains with a retained Cube orientation ${ }^{10}$. In the present ETP copper the predominant texture components are Rotated Brass (RB), Goss, Cube RD and Cube. In the case of the FRHC copper the predominant texture components are Goss, $\mathrm{P}$ followed by Rotated Brass and Cube RD.

Figure 3 summarizes the intensity values of each component presented in both coppers. The ETP copper presents components oriented in recrystallization directions, like $<111>,<112>$ and $<100>$, while the FRHC copper has a strong presence of deformation components transitioning to recrystallization components such as $\mathrm{P}\{011\}<122>$. It is observed in both coppers the prevalence of the $<110>\quad$ Z fiber, with a slightly lower frequency for the $<110>$ Y fiber, and a marked difference in the case of $<110>\| \mathrm{X}$ fiber. However, the ETP copper, also shows a preference of the $<111>$ and $<100>\| \mathrm{X}$ fibers. Again, this
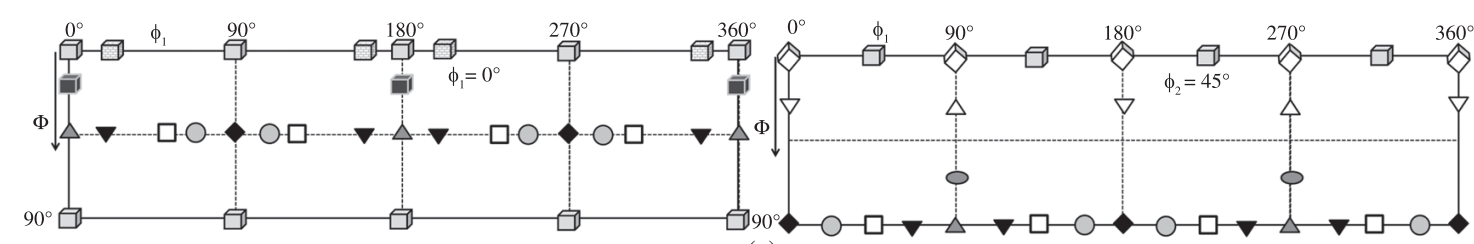

(a)

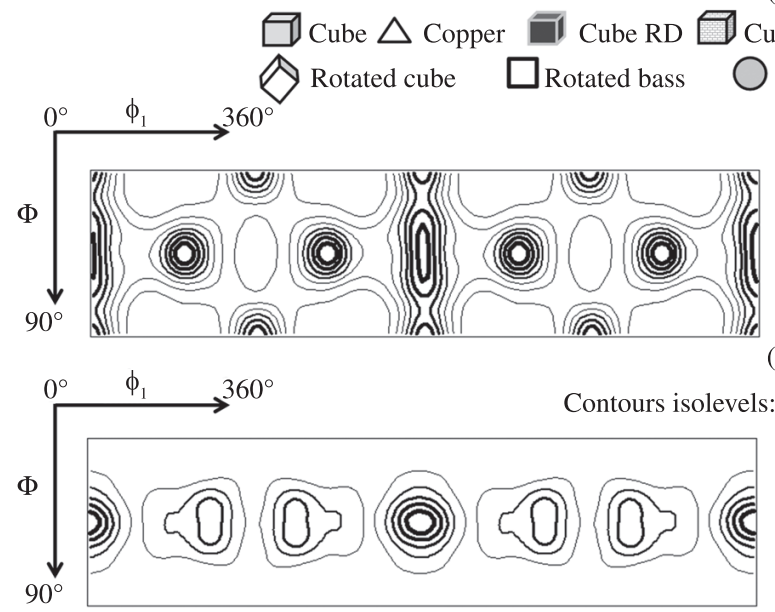

(b)
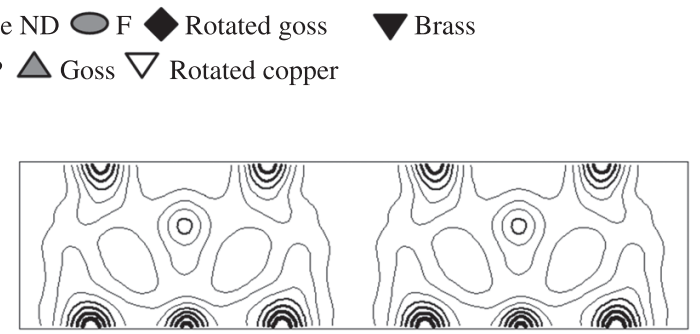

Brass

P $\triangle$ Goss $\nabla$ Rotated copper

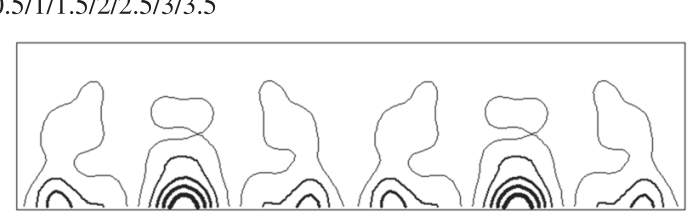

(c)

Contours isolevels: $0.5 / 1 / 1.5 / 2 / 2.5 / 3$

Figure 2. ODF (a) ideal, (b) ETP copper and (c) FRHC copper after annealing at $600{ }^{\circ} \mathrm{C}$. 
behavior indicates that the two materials exhibit a slight anisotropy even after annealing.

Material deformed by ECAP. The evolution texture during ECAP is governed by three factors in a greater or lesser extent: applied deformation (which depends on the die configuration $(\Phi)$, number of passes $(N)$ and processing route), deformation mechanism (slip and twinning systems) and initial texture. However when the ECAP dies have a $\psi>0^{\circ}$ a special case appears, because the applied strain is not entirely homogeneous due to the presence of a continuous distribution of shear planes, which contributes to an additional deviation in the texture evolution from the simple shear model ${ }^{11}$. In order to study the ECAP processing textures for both coppers the triclinic symmetry $\left(0<\varphi 1<360^{\circ}\right)$ was assumed, which refers to a $360^{\circ}$ rotation about the TD axis ( $\mathrm{z}$ axis) of the matrix and the ideal orientations given by Beyerlein et al. ${ }^{5}$ and $\mathrm{Li}$ et al. ${ }^{6}$ were used. Figures 4, 5 and 6 summarize the texture evolution of the two materials deformed by ECAP. In this investigation, a monoclinic symmetry $\left(0<\varphi 1<180^{\circ}\right)$ can be noticed in both coppers, which were determined both by a symmetry in the components every $180^{\circ}$ and by the almost uniform intensity of their $\mathrm{B} / \bar{B}, \mathrm{~A} / \overline{\mathrm{A}}$ components. This is somehow contradictory with some results reported in the literature where the latter behavior is only observed when the material is processed by ECAP following route $\mathrm{A}$ or $\mathrm{C}$, but not when processing by route $\mathrm{Bc}$ where a triclinic symmetry is usually observed ${ }^{5}$.

In FCC materials, simple shear deformation occurs along two main fibers, namely, the $\beta$ fiber or $<110>$ fiber (which is parallel to the shear direction) and moves from the $\mathrm{C}$ component to the $\bar{B}$ and $\overline{\mathrm{A}}$ components, and the $\alpha$ fiber, or $\{111\}$ fiber (where $\{111\}$ is parallel to the shear plane), which is subdivided into two partial fibers: the $A_{1}$ fiber that travels from $\bar{A}$ component to the $\mathrm{A}_{1}$ * component

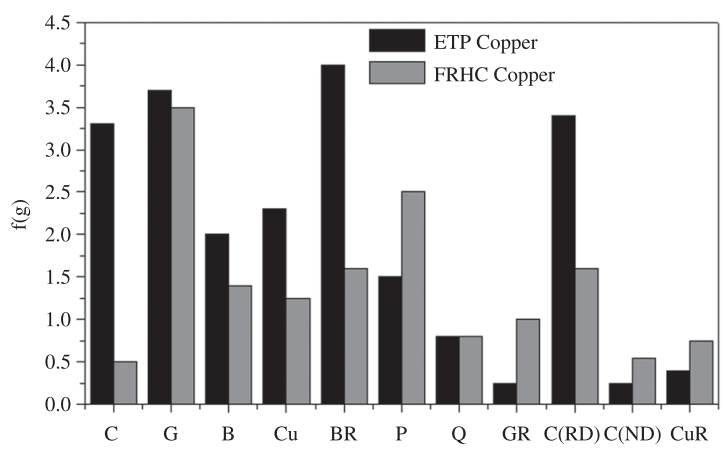

(a) Texture component

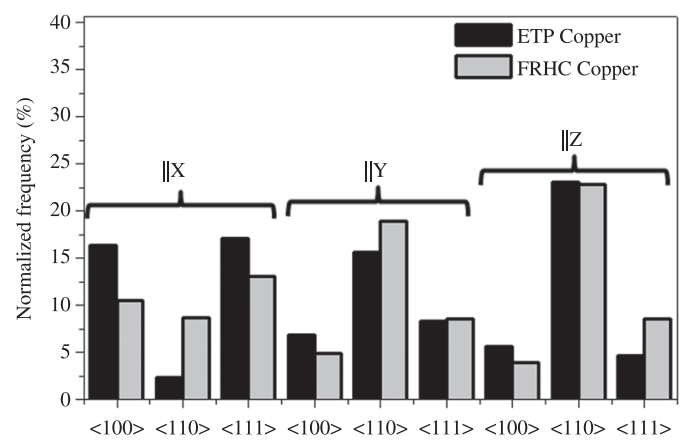

(b) Fiber texture

Figure 3. (a) Texture component frequency and (b) texture fibers of the initial materials.
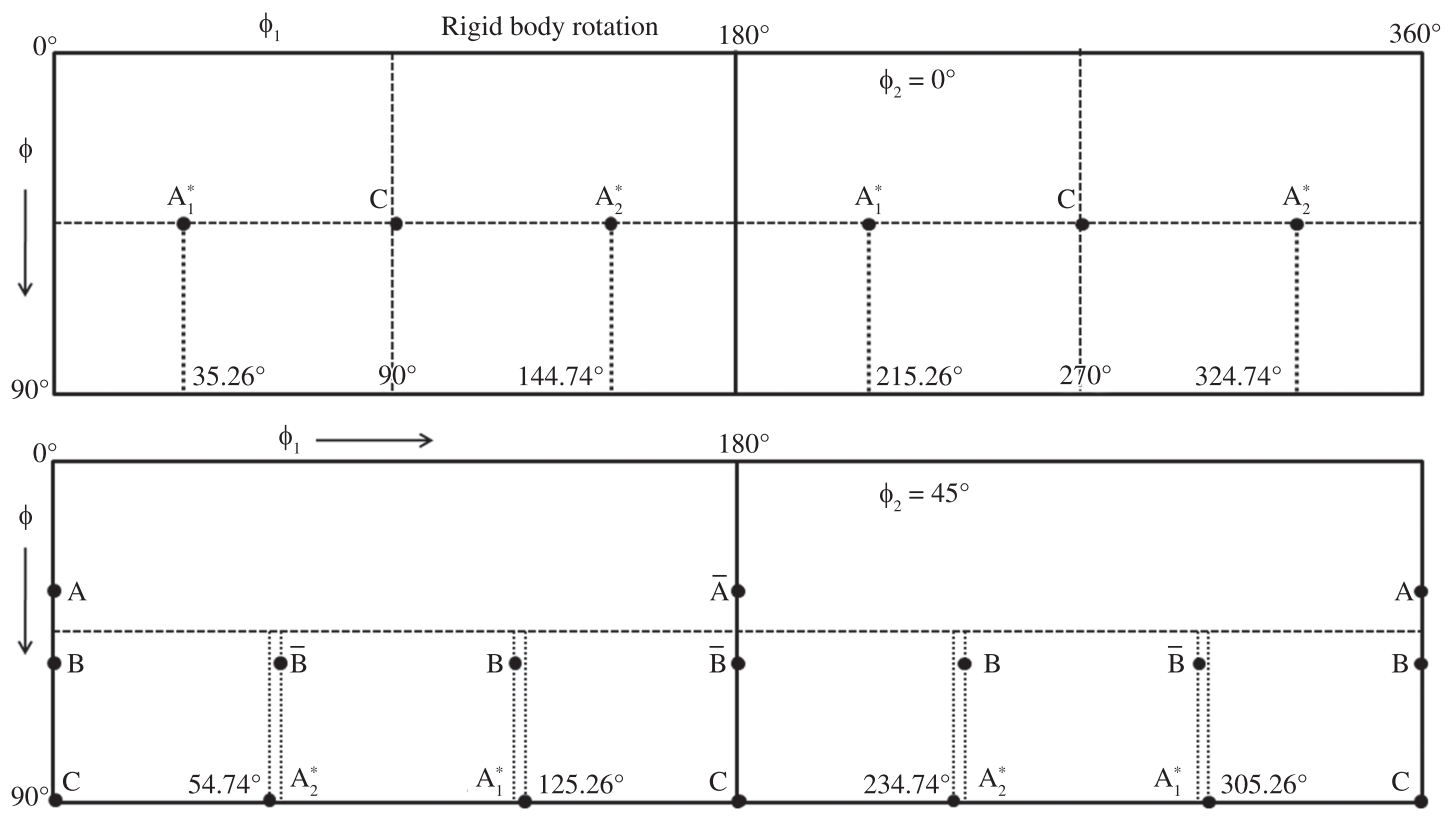

Figure 4. Ideal ODFs in triclinic symmetry of FCC metals deformed by simple shear. 
and the $\mathrm{A}_{2}$ fiber moving from the $\mathrm{A}$ component to the $\mathrm{A}_{2}$ * component $^{12}$ (see Figure 4).

After the first pass, the two materials display the preferred $\beta$ deformation fiber, due to the higher proportion of $\mathrm{C}$ component, with a moderate presence of $\mathrm{B} / \bar{B}$, $\mathrm{A} / \overline{\mathrm{A}}$ components. This is consistent with the investigation of Suwas et al. ${ }^{13}$, who reported that different purity coppers with a strong initial texture oriented in the $\langle 110\rangle$ fiber presents after the first ECAP pass, the presence of a strong $\mathrm{C}$ component. However, Beyerlein et al. ${ }^{5}$ reported that if the texture after the first pass is weak, $A_{1}^{*}$ is the main component in the second pass and the $\mathrm{B} / \bar{B}$ components gradually strengthen with increasing number of ECAP passes.

After the fourth pass the ETP copper develops (Figure 5) additional components and orientations like twinned cube type, twinned Goss and twinned brass are observed to those generated by simple shear, indicating the presence of a recrystallization process during the ECAP process. Toth et al. ${ }^{12}$ associated the presence of these components to a dynamic recrystallization process. Regarding the FRHC copper (Figure 6), after the fourth pass, a preferential $\alpha$ fiber with a moderate influence of the $\beta$ fiber was observed. This may indicate a regenerated and random texture which indicates deformation patterns by the ECAP process ${ }^{7}$.

In order to prove the ability of the recrystallization process to take place during or after the ECAP process, a thermal analysis of the same materials through the differential scanning calorimetry technique was realized.
The DSC tests showed that after the fourth ECAP pass in the ETP copper, a significant reduction of the recrystallization temperature to values lower than $125{ }^{\circ} \mathrm{C}$ was obtained ${ }^{14}$. Correlating these results with the ones obtained from a parallel research conducted by Grané ${ }^{15}$, where by means of finite element simulations of the present experimental setting, the sample temperatures were estimated. He obtained sample temperatures as high as $84.4{ }^{\circ} \mathrm{C}, 104.7^{\circ} \mathrm{C}$ and $164.6^{\circ} \mathrm{C}$ after one ECAP pass depending of the simulated friction coefficient $\mu,(0,0.05$ and 0.1 respectively). Accordingly, the reached deformation temperatures would be high enough to promote an in-situ annealing. This recrystallization process could explain the additional texture components that appear after the ECAP processing.

In the eighth pass, the ETP copper showed a similar behavior to the FRHC copper. The presence of the $\alpha$ fiber has a greater influence than the $\beta$ fiber, especially of its $\mathrm{A}_{1}^{*}$ and $\mathrm{A}_{2} *$ components. This behavior continues until the sixteenth pass, with a sequential reduction of the $\mathrm{C}$ component but with a significant increase of the components associated to the $\beta$ fiber such as $\mathrm{B} / \bar{B}$ and $\mathrm{A} / \overline{\mathrm{A}}$.

Regarding the anisotropy of the two materials during the ECAP process (see Figure 7) a preference of two main fibers <110> $\| \mathrm{X}$ (extrusion direction) and <111> || Y (perpendicular to the shear plane) was observed, resulting with the presence of components like $\mathrm{C}(\{001\}<110>)$,

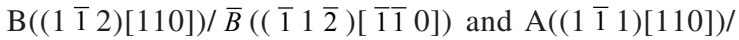
$\overline{\mathrm{A}}((11 \overline{1})[\overline{1} \overline{1} 0])$, which are characteristics of a material subjected to simple shear. However, the presence of the

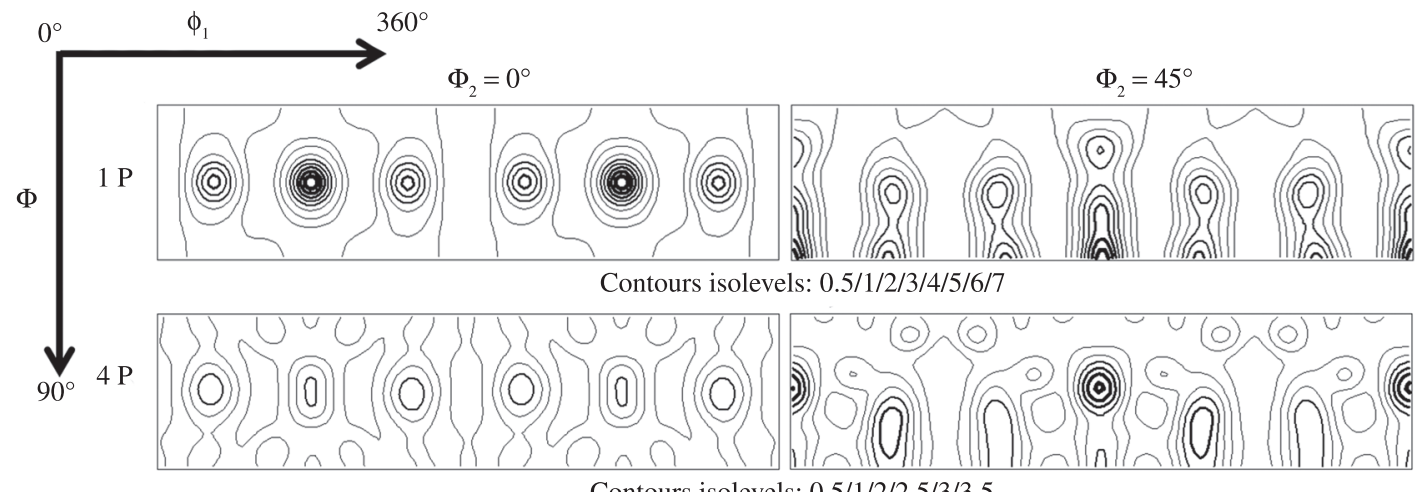

Contours isolevels: $0.5 / 1 / 2 / 2.5 / 3 / 3.5$

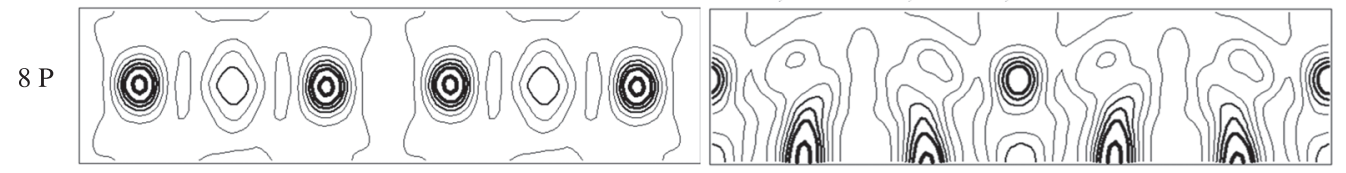

Contours isolevels: 0.5/1/1.5/2/2.5/3/4

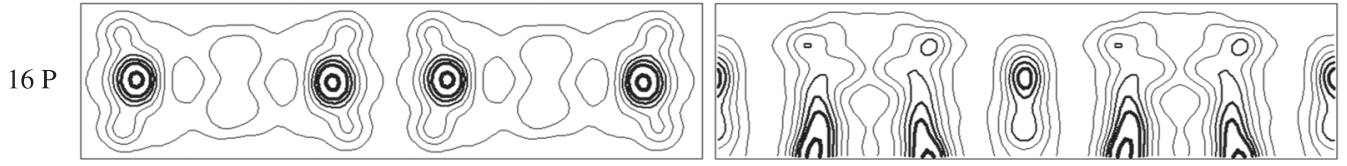

Contours isolevels: $0.5 / 1 / 1.5 / 2 / 2.5 / 3 / 4$

Figure 5. ODFs of ECAPed ETP copper. 
$<110>\| \mathrm{Z}$ fiber which comes from the annealed material is observed. This fiber remains practically unchanged during ECAP. A significant reduction according to the deformation patterns would be expected, but the behavior presented by the $<110>\| \mathrm{Z}$ fiber could be explained by: 1) the presence of recrystallization components and 2) the accommodating of deformation through crystal rotations during crystallographic sliding along primary and secondary slip systems ${ }^{16}$. These crystal rotations promote the formation of special grain boundaries with twin character, especially $\sum 3\left(60^{\circ}<111>\right), \sum 9\left(38.94^{\circ}\right.$ $<110>)$, and $\sum 27 \mathrm{a}\left(31.58^{\circ}<110>\right)$ among others. This confirms the heterogeneity in the evolution of the texture imparted for this process, especially when using ECAP dies with $\Psi>0^{\circ}$. Another important factor to take into account is the predisposition of the material to deform by the preferred fiber of the initial annealed material. In this case both materials had a preference towards $\beta$ or $<110>$ fiber.

In order to get a better understanding of the fiber components during the ECAP process it would be interesting a deep study on the axis rotation based on inverse pole figures. This analysis has not been included here for space saving purposes and it would be done in a parallel work.

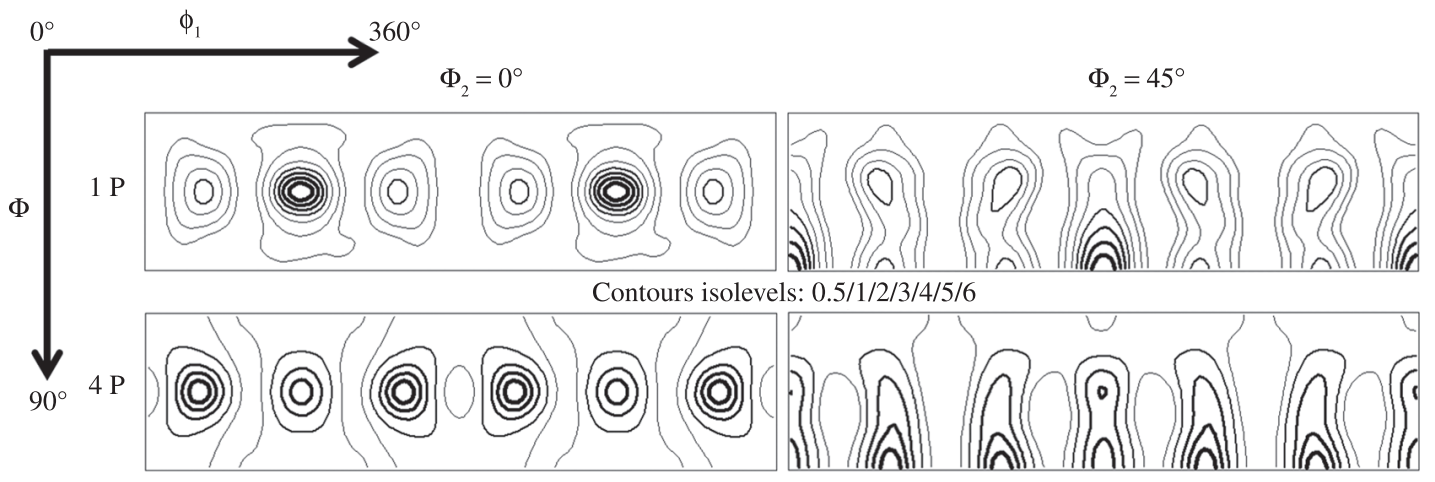

Contours isolevels: 0.5/1/2/3/4

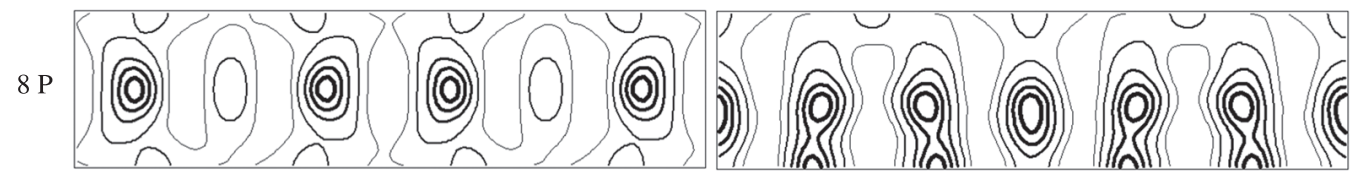

Contours isolevels: $0.5 / 1 / 2 / 3 / 4$

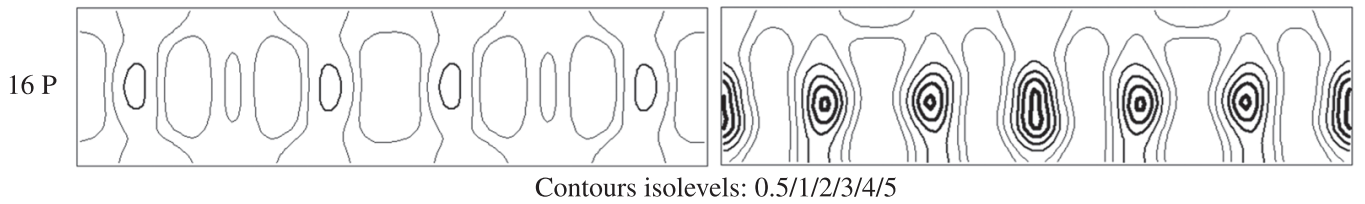

Figure 6. ODFs of ECAPed FRHC copper.
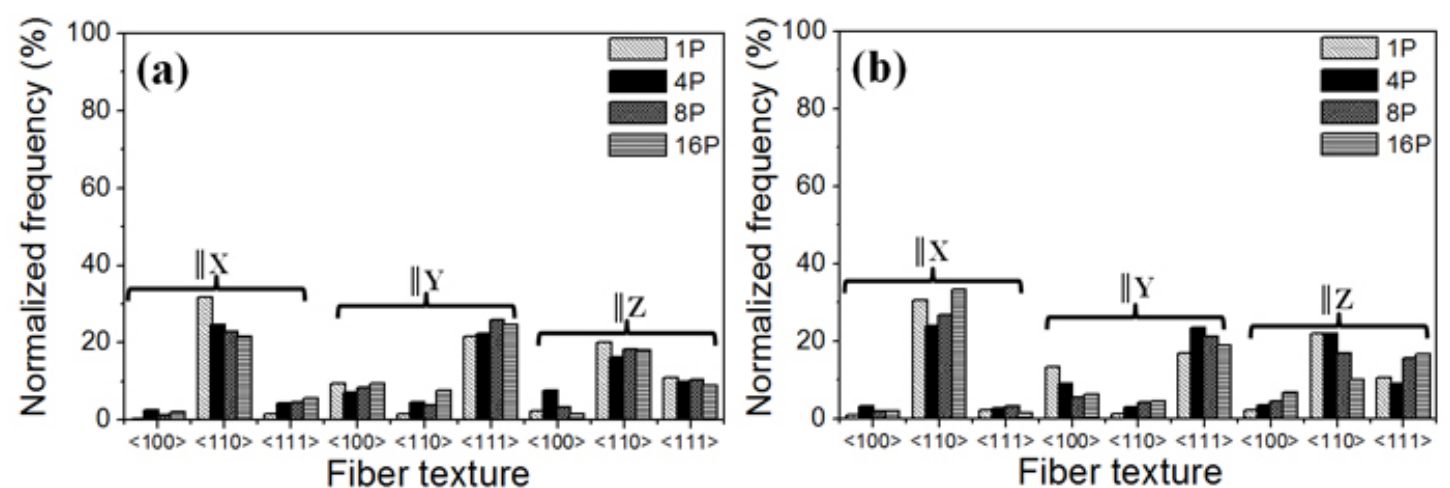

Fiber texture

Figure 7. Fiber texture frequency after the ECAP process for (a) ETP and (b) FRHC copper. 


\section{Conclusions}

The texture of two coppers ETP and FRHC were analyzed through the orientation distribution function. The presence of preferred textures, especially of the $\langle 110\rangle$ fiber in the initial annealed material prior to ECAP allows deformation preferably through the $\beta$ fiber, especially by its $\mathrm{C}$ and $\mathrm{B} / \bar{B}$ components for the ETP copper and $\mathrm{C}, \mathrm{B} / \bar{B} \mathrm{y}$ $\mathrm{A} / \overline{\mathrm{A}}$ for the FRHC copper, which is seen in the increment of the $<110>\| X$ deformation fiber. The high normalized frequency of the $<111>\| \mathrm{Y}$ can be explained by the presence of the $\alpha$ fiber in both coppers processed by ECAP, while the $<110\rangle \| Z$ deformation fiber could be correlated to the initial texture, since after the first pass for the ETP copper and after the fourth pass for the FRHC copper the values of the $<110>\| Z$ deformation fiber maintain the same range as in the annealed coppers. In the following passes a reduction of the $<110>\| Z$ deformation fiber can be seen,

\section{References}

1. Karaman I, Haouaoui M and Maier HJ. Nanoparticle consolidation using ECAE at room temperature. Journal of Materials Science. 2007; 42:1561-1576. http://dx.doi. org/10.1007/s10853-006-0987-6

2. Stoica GM, Fielden DE, McDaniels R, Liu Y, Huang B, Liaw PK et al. An analysis of the shear zone for metals deformed by ECAP. Materials Science and Engineering: A. 2005; 410:239-242. http://dx.doi.org/10.1016/j. msea.2005.08.186

3. Li S, Beyerlein IJ, Alexander DJ and Vogel SC. Texture evolution during ECAE: Effect of initial texture from experiment and simulation. Scripta Materialia. 2005; 52:1099-1104. http:// dx.doi.org/10.1016/j.scriptamat.2005.02.008

4. Dalla Torre FH, Gazder AA, Gu CF, Davis CHJ and Pereloma EV. Grain size, misorientation, and texture evolution of copper processed by ECAE and the validity of the Hall-Petch relationship. Metallurgical and Materials Transactions A. 2007; 38:1080-1095. http://dx.doi.org/10.1007/s11661007-9103-Z

5. Beyerlein IJ and Tóth LS. Texture evolution in ECAE. Progress in Materials Science. 2009; 54:427-510. http://dx.doi. org/10.1016/j.pmatsci.2009.01.001

6. Li S, Beyerlein IJ and Bourke MAM. Texture formation during ECAE of FCC and BCC materials: comparison with simple shear. Materials Science and Engineering: A. 2005; 394:66-77. http://dx.doi.org/10.1016/j.msea.2004.11.032

7. Valiev $\mathrm{R}$ and Langdon TG. Principles of ECAP as a processing tool for grain refinement. Progress in Materials Science. 2006; 51:881-981. http://dx.doi.org/10.1016/j. pmatsci.2006.02.003 with a subsequent increment in the $<111>\| \mathrm{Z}$ deformation fiber for the FRHC copper. The preference of both materials to these deformation fibers could confirm the anisotropy of the ECAP process. Also the presence of recrystallization components for both materials after ECAP was observed, which can be due to the reduction of the recrystallization temperature with the number of ECAP passes and to the thermal influence generated during deformation. This feature was more evident in the ETP copper.

\section{Acknowledgements}

The authors acknowledge the funding received through the project CICYT MAT 2.008-06.793-C02-01 and Nucli RD10-1-0048 and the support of I. Lopez-Insa (SEM) from UPC. The authors also thank La Farga Lacambra for donating the material and its technical assistance.

8. Humphreys FJ and Hatherly M. Recrystallization and related annealing phenomena. 2nd ed. Oxford: Pergamon press; 2004.

9. Segal VM. Equal channel angular extrusion: from macromechanics to structure formation. Materials Science and Engineering: A. 1999; 271:322-333. http://dx.doi.org/10.1016/ S0921-5093(99)00248-8

10. Engler $\mathrm{O}$ and Randle V. Introduction to texture analysis. 2 nd ed. CRC Press-Verlag; 2010.

11. Segal VM. Slip line solutions, deformation mode and loading history during equal channel angular extrusion. Materials Science and Engineering: A. 2003; 345:36-46. http://dx.doi. org/10.1016/S0921-5093(02)00258-7

12. Tóth LS, Jonas JJ, Daniel D and Bailey JA. Texture development and length changes in copper bars subjected to free end torsion. Textures and Microstructures. 1992; 19:245-262. http://dx.doi. org/10.1155/TSM.19.245

13. Suwas S, Arruffat-Massion R, Tóth LS, Fundenberger JJ, Eberhardt A and Skrotzki W. Evolution of crystallographic texture during ECAE of copper: The role of material variables. Metallurgical and Materials Transactions A. 2006; 37:739-753. http://dx.doi.org/10.1007/s11661-006-0046-6

14. Higuera OF and Cabrera JM. Microstructure, mechanical properties and thermal evolution during equal channel angular pressing of fire refined high conductivity copper. Mechanics of Materials. 2012. Submitted for publication.

15. Grané M. Personal communication. 2012.

16. Winther G. Slip systems extracted from lattice rotations and dislocation structures. Acta Materialia. 2008; 56:1919-1932. http://dx.doi.org/10.1016/j.actamat.2007.12.026 